\title{
The Relationship between Teacher Turnover and School Performance
}

\author{
PETER DOLTON \\ Newcastle University, UK \\ DAVID NEWSON \\ Institute of Education, University of London, UK
}

ABSTRACT This article explores the relationship between teacher turnover and school performance. It uses a database of 316 primary schools in six London Local Education Authorities derived by merging Government data on teachers and schools. This rich data includes school-level variables on teacher turnover matched to school characteristics. The study shows that high levels of teacher turnover can be shown to have detrimental effects on pupil progress and achievement.

\section{Introduction}

The problem of teacher supply has been much debated in both the US and UK for decades. The discussion has focused on a number of issues. These have included the overall numbers and quality of entrants to teaching, recruitment in specific shortage subjects such as maths and science and the problems of teacher supply in high cost regions. A number of policy solutions have been proposed which have been targeted at improving both recruitment and retention in these areas. These ideas often relate to improvements in teachers' pay and conditions. However, the debate in the UK in recent years has largely ignored the differences that exist between schools in terms of school characteristics. Our argument is that the nature of the school environment can constrain the potential for teacher supply to respond effectively to shortages in a significant minority of, often socially deprived, schools.

The position of schools in poorer localities and with a disadvantaged intake has an important impact on the issue of equity as a goal of UK government education policy. Educational disadvantage and social exclusion in schools, in all its forms (see Sparkes, 1999), is difficult to combat and is quite properly an important target for education policy. As a result, equality of opportunity features prominently in the official strategy of the Department for Education and Skills (DfES). This strategy requires that every child must have the opportunity to realise their full potential (DfES, 2002). Furthermore, the link between poverty and underachievement is recognised and compensatory policies are outlined to direct extra resources into deprived areas. However, such policies will be undermined if, due to a particular set of school characteristics, teacher turnover is significantly higher in schools with a more deprived intake. 
These issues are closely connected to the market or quasi-market reforms in the UK education system in the last ten to fifteen years. Parental choice has caused schools to begin to compete for pupils. This process has been aided by the publication of a range of performance indicators such as exam league tables and OFSTED reports. While some commentators have suggested these reforms have been a factor contributing to overall rises in teacher turnover (see Wiggins \& Tymms, 2000), the particular effects on poorer schools have not been widely studied.

This study aims to investigate how teacher turnover varies in relation to the average level of social deprivation in a school. Our first hypothesis is that schools with a poorer intake, which typically have a range of characteristics, such as high free school meal entitlement, low academic attainment and higher than average percentages of ethnic minority and special needs children, will also experience a higher than average level of teacher turnover. Our second hypothesis is that there may be an effect of teacher turnover on pupil attainment. Our specific research questions are:

- Do primary schools in socially deprived areas and with socially deprived intakes have a higher than average turnover of teachers?

- Is there a relationship between teacher turnover and other primary school characteristics such as SATS scores, the percentage of ethnic minority pupils, the percentage of special needs pupils, the pupil-teacher ratio and the size of the school?

- Is there any evidence to suggest that the attainment levels in schools are affected by teacher turnover?

\section{The Context of the Relationship Between Teacher Turnover and School Performance}

In the UK the DfES model attempts to bring teacher demand and supply into equilibrium so there is neither a shortage of teachers or an oversupply. However estimates by commentators such as Dolton (2001) based on numbers of school age children, the desired pupil-teacher ratio and the number of teachers employed show that there has been a shortfall of teachers for some of the period since 1946 averaging between 30,000 and 40,000 teachers. The DfES has mostly been successful in predicting demand, but the shortfall in teacher numbers has occurred because of the inadequacy of teacher supply during this period. Despite the shortfall, vacancy rates published by the DfES have rarely been above $1 \%$ (DfES 2001). Schools seem to have used a number of coping strategies such as employing teachers from abroad, using temporary supply teachers or increasing pupil teacher ratios to deal with the shortages.

The UK literature emphasizes that the effects of teacher shortages have not been felt equally in all areas. Different regions of the country, different subject areas and levels of responsibility and different types of school have all been affected differently. The literature has documented in detail how the national pay scales applicable to all teachers have caused shortages in regions with a high cost of living such as London and high demand subjects such as IT.

The recruitment and retention problems for an area such as London have been highlighted by Hutchings (1999). She found that the teaching workforce in London has become significantly different from the national norm in ways that cause a number of problems. Teachers in London are much younger on average than the rest of the country. Whereas approximately $38 \%$ of London teachers were under 35 , the comparable figure nationally was only $27 \%$. Hutchings also found that these teachers often envisage only a short stay in the capital. She found $41 \%$ of all London teachers expected to leave the city within five years. Such trends cause much higher rates of turnover and wastage in London 
than in other areas. Turnover and wastage rates in 1997-98 were between 40 to 50\% higher in Inner London than in the North East. In addition, schools find it very difficult to fill responsibility and management jobs in London, with over $50 \%$ of primary responsibility posts in 1998-99 receiving less than 3 applicants.

The literature of teacher supply in the US and in Britain essentially divides into two main camps to explain teacher shortages. One body of opinion, represented in the UK by commentators such as Zabalza (1979) and Dolton (2001) and in the US by Steinbrickner (1998) and Theobald (1990), advocates the influence of teachers' relative pay as the primary determinant of teacher recruitment and retention. For this group difficulties in teacher supply can be solved by an increase in salary large enough to have the required impact in a given set of market conditions. These pay rises can either be across the board or targeted to solve supply problems in shortage subjects or regions with a high cost of living. Much of this evidence comes from individual data and models graduate decisions in the labour market.

An alternative set of ideas emphasises the influence of non-pecuniary factors on decisions to enter or leave teaching. Several recent studies in the US (Mont \& Rees, 1996; Hanushek, 2001; Ingersoll, 2000) suggest a teacher's motivation to enter or leave the profession is determined by factors such as job satisfaction, school characteristics or conditions of work, just as much as relative salary. This group of commentators points out that there is a high level of variation in teacher recruitment and retention rates between schools with different characteristics and in different subject areas. On the whole they find that schools in the US with a more socio-economically deprived intake, with lower academic progress and with a higher percentage of non-white children have more difficulties recruiting and retaining staff. They see these school characteristics as a proxy for poor working conditions within that institution. Therefore, for this group of commentators, teacher recruitment and retention problems can only be improved if teacher's working conditions generally, and the particularly poor conditions present in some schools, are improved.

However, the position of teacher recruitment and retention in schools with a socially deprived intake has received little attention in the UK since a 1970's study by Zabalza et al. (1979). Zabalza's research, based on teachers' pension records, found that socially deprived schools had worse staffing characteristics than the national norm in three ways. They had more unqualified teachers, more untrained graduates, a higher turnover and more problems attracting experienced teachers. He also found that the introduction of extra pay for teachers in these schools in the late 60's (the Social Priority Allowance) had only had marginal and shortterm effects in improving their staffing position, which on the whole remained significantly worse than schools with a more affluent intake.

The Social Priority Allowance was removed from the teacher pay structure in the late 1980's to be replaced by Local Education Authority (LEA) funding formulas designed to make available greater funds for teacher recruitment and retention to schools with higher levels of deprivation amongst their pupils. There is a need to update Zabalza's research to establish if this group of schools still have greater staffing problems than other schools and if it is pecuniary or non-pecuniary factors that are the key to attracting and retaining teachers in these areas.

\section{The North London Primary Schools' Database}

This study uses quantitive methods, aiming to answer the research questions through statistical analysis of a database of 316 primary schools in six London borough LEAs namely Islington, Hackney, Haringey, Camden, Enfield and Barnet. These LEAs represent the north central area of the city. They have been chosen because of their proximity, which reduces the chance of other geographical factors affecting the data and allows the possibility of spill over 
effects between areas. In addition they represent a good cross-section of the variety of conditions found in London, as three are inner city (Camden, Islington and Hackney), two are outer boroughs and one (Haringey) lies in-between.

To make the database more homogeneous in terms of the schools used, only LEA funded state schools have been included. In addition, only data from primary (3 to 11 ) or junior ( 7 to 11) schools is used. Infant (3 to 7), secondary (11 to 18) and private schools have been excluded from the database. The database has been constructed from a number of sources.

The Database of Teacher Records (DTR)

The DTR is a database of teachers' pension records. It is completed on a yearly basis and records teachers serving in a school on the 31 March. It also records those who have left in previous years, if they have not obtained a teaching job elsewhere. Access has been given by the DfES to the years 1995 to 1999 for the six London Boroughs in the database. Using these records it is possible to calculate the percentage of teachers in a school who leave during a given year. Figures for each school have been obtained for 1996, 1997, 1998 and 1999 and these are used in the data as measures of each school's teacher turnover.

One limitation of our data is that the DTR does not follow what happens to teachers who exit from a particular school. Hence we do not know the relative proportions of those leaving a particular school between that going to another school and that quitting the profession completely. As a result we are not in a position to know whether the higher levels of turnover at more deprived schools are because some of the teachers are 'trading up' to more advantaged schools.

Local Education Authority Statistical Information Service (LEASIS) Data

Data has also been obtained from LEASIS, a DfES database containing information on individual school characteristics in a number of areas including:

- The percentage of children claiming free school meals i.e., children whose parental income is low enough to entitle them to this means tested state benefit.

- The percentage of children with special educational needs (both with and without statements).

- The percentage of children from ethnic minority groups.

- The pupil-teacher ratio.

- The school results in the 2001 Key Stage 2 English and Maths Standard Attainment Tests (SATS). The percentage of year 6 children (10 and 11 years old) scoring level 4 and above is used.

- Whether the school is community (i.e., solely LEA funded) or voluntary aided or controlled (i.e., has a source of additional funding such as a religious organisation).

In order to construct the overall database the DTR leavers' data for each school has been combined with the LEASIS data. This proved difficult in twelve cases. This was due to alterations in LEA school numbers caused by factors such as changes in school name, amalgamations of junior and infant schools and schools that are newly opened. As a result these 12 schools (out of 316 in the database) do not have any leavers' data.

\section{Methodology and Results}

A crucial question to ask in this area is the nature of the simultaneous relationship between school performance and teacher turnover. Clearly the two variables are co-determined 
within any given year. This means there is a classic econometric identification problem. We suggest that simultaneity bias is not an issue in our data as our pupil attainment is measured in 2001, whereas our teacher turnover is measured over the 1996-99 period. We suggest it is reasonable to assume that the teacher resources they experienced whilst younger will have affected pupils SATS performance. Likewise we suggest that pupil exam results in 2001 will be a satisfactory proxy for the educational attainment achieved by pupils over their previous five years at the school. Hence the interpretation of our econometric model is that teacher turnover will be conditional on the average pupil performance in recent years and that this performance will act as a satisfactory proxy for previous pupil attainment in explaining teacher turnover 3-5 years later. As a result we proceed by analysis of these separate 'reduced form' equations.

In order to answer the research questions about teacher turnover a series of multiple regressions are estimated. The dependent variables in these regressions are teacher turnover figures at different points in time. The explanatory variables are the school characteristics from the LEASIS data and the schools 2001 English and Maths SATS results. These variables are reversed for the last research question, where SATS results become the dependent variable and the turnover data is used as an explanatory variable.

There is a considerable degree of variation in the turnover results from the six LEAS used in the database. As can be seen from Table 1, Hackney recorded a teacher turnover rate almost one and a half times higher than Enfield.

These summary statistics by LEA indicate a substantial degree of heterogeneity with respect to teacher turnover by geography. We will therefore control for this diversity by including a dummy variable for each LEA using Haringey as the reference category. Haringey is chosen for this role as it is in-between the inner London boroughs, which have higher turnover rates, and the outer boroughs which have lower scores for this variable. (Choosing any other of the six LEAs, as the reference category would make no significant impact on the results of the regression analysis as this merely shifts the value of the intercept term).

In addition, it is found that the SATS variables for English and Maths have a high correlation (0.8). These two variables can therefore be considered to be co-linear. As a result, each regression is run separately for each of these variables, as their presence together in a regression calculation would be likely to distort the results.

The first research question examines whether primary schools in socially deprived areas and with socially deprived intakes have a higher than average turnover of teachers. Furthermore, the relationships between teacher turnover and other school characteristics such as SATS scores are investigated. These research questions require multiple regressions of the teacher turnover variable and the full range of school characteristic variables. This will show the strength of the relationships between school characteristics and teacher turnover. The results from these regressions are shown in table 2.

Table 1 Teacher turnover means for each LEA

\begin{tabular}{lc}
\hline Borough & Teacher Turnover Mean \\
\hline Camden & 20.85 \\
Hackney & 34.56 \\
Islington & 20.89 \\
Haringey & 17.79 \\
Enfield & 14.87 \\
Barnet & 17.64 \\
\hline
\end{tabular}


Table 2 The relationship between turnover and school characteristics

\begin{tabular}{|c|c|c|}
\hline & $\begin{array}{l}\text { Teacher turnover } \\
\text { (\% of teacher leavers) } \\
\text { 1996-99 } \\
\text { With English SATS }\end{array}$ & $\begin{array}{l}\text { Teacher turnover } \\
\text { (\% of teacher leavers) } \\
1996-99 \\
\text { With Maths SATS }\end{array}$ \\
\hline $\begin{array}{l}\text { School characteristic } \\
\text { variables }\end{array}$ & $\begin{array}{l}\text { Unstandardized } \\
\text { coefficients } \\
\text { (T-test in brackets) }\end{array}$ & $\begin{array}{l}\text { Unstandardized } \\
\text { coefficients } \\
\text { (T-test in brackets) }\end{array}$ \\
\hline English SATS & $-0.096(-2.35)^{* *}$ & - \\
\hline Maths SATS & - & $-0.087(-2.50)^{* *}$ \\
\hline Free school meals & $0.095(1.75)^{*}$ & $0.110(2.16)^{* *}$ \\
\hline Camden & $2.984(1.69)^{*}$ & $2.883(1.65)^{*}$ \\
\hline Hackney & $14.308(8.92)^{* *}$ & $14.516(9.05)^{* *}$ \\
\hline Islington & $0.951(0.57)$ & $1.050(0.63)$ \\
\hline Enfield & $2.945(1.53)$ & $2.852(1.48)$ \\
\hline Barnet & $-1.711(-0.99)$ & $-1.613(-0.93)$ \\
\hline Community/voluntary aided & $1.762(1.80)^{*}$ & $1.791(1.84)^{*}$ \\
\hline Ethnic minority pupils & $0.018(0.53)$ & $0.016(0.47)$ \\
\hline Special needs pupils & $0.039(-0.78)$ & $-0.032(-0.64)$ \\
\hline Pupil/teacher ratio & $0.270(1.33)$ & $0.243(1.20)$ \\
\hline Constant & $15.671(2.42)^{* *}$ & $14.984(2.41)^{* *}$ \\
\hline $\mathrm{R}$ squared & 0.4617 & 0.4630 \\
\hline Adjusted R squared & 0.4387 & 0.4401 \\
\hline Probability > F & 0.000 & 0.000 \\
\hline No. of observations & 294 & 294 \\
\hline
\end{tabular}

*, ** significant at $10 \%$ and $5 \%$ level respectively

Using FSM as the best available measure of social deprivation, the regression shows this variable to be a statistically significant determinant of teacher turnover. As the percentage of FSM children in a school increases so does the teacher turnover. The result is slightly weaker when English SATS are included in the regression (significant at the 10\% level), than when Maths SATS are used (significant at the 5\% level). The coefficients for FSM show us that an increase of $10 \%$ in the number of children eligible for free school meals increases teacher turnover by approximately $1 \%$. These results can be further illustrated using descriptive statistics. The quartile of most deprived schools has an average percentage of leavers of 26.6, more than one in four teachers leaving every year. That is almost 50\% higher than other schools, where just fewer than one in five teachers can be expected to leave annually.

For research question two a mixed picture emerges. Both English and Maths SATS scores have a statistically significant relationship (at the $5 \%$ level) with teacher turnover. As SATS scores increase, teacher turnover declines. The coefficients for the SATS scores tell us that a $10 \%$ increase in the percentage of pupils scoring level 4 or above will reduce teacher turnover by just less than $1 \%$. In terms of descriptive statistics this means that schools in the lowest quartile for academic achievement record, on average, almost 50\% more leavers in a given year.

The only other school characteristic that records a significant relationship to teacher turnover is whether the school is community or voluntary aided. This variable is significant at the $10 \%$ level. It shows us that voluntary aided schools in the database have lower teacher 
Table 3 The effect of school characteristics on SATS scores

\begin{tabular}{lcc}
\hline & English SATS scores & Maths SATS scores \\
\hline School characteristic variables & Unstandardized & Unstandardized \\
& coefficients & (T-test in brackets) \\
& (T-test in brackets) & \\
\hline & & $-0.250(-2.50)^{* *}$ \\
Average teacher turnover '96-'99 & & $0.529(6.54)^{* *}$ \\
Free school meals & $-0.201(-2.35)^{* *}$ & $12.150(4.22)^{* *}$ \\
Camden & $-0.639(-9.24)^{* *}$ & $6.352(2.07)^{* *}$ \\
Hackney & $12.042(4.89)^{* *}$ & $5.676(2.03)^{* *}$ \\
Islington & $3.229(1.23)$ & $-1.089(-0.33)$ \\
Enfield & $4.107(1.71)^{*}$ & $-3.597(-1.23)$ \\
Barnet & $-0.102(-0.04)$ & $1.715(1.03)$ \\
Community/voluntary aided & $-4.248(-1.70)^{*}$ & $0.051(0.89)$ \\
Ethnic minority pupils & $1.216(0.86)$ & $-0.099(-1.18)$ \\
Special needs pupils & $0.065(1.32)$ & $0.201(0.59)$ \\
Pupil/teacher ratio & $-0.165(-2.29)^{* *}$ & $91.638(10.06)^{* *}$ \\
Constant & $0.462(1.58)$ & 0.4358 \\
R squared & $90.239(11.58)^{* *}$ & 0.4117 \\
Adjusted R squared & 0.5773 & 0.000 \\
Probability $>$ F & 0.5593 & 294 \\
No. of observations & 0.000 & \\
\hline & 294 &
\end{tabular}

*, ** Significant at $10 \%$ and $5 \%$ level respectively

turnover than community schools. The coefficient for this variable shows that community schools lose on average approximately $1.8 \%$ more teachers than voluntary aided schools.

The next research question to examine is whether there is any evidence to suggest that the attainment levels in schools are affected by teacher turnover. For this regression the dependent variables must be English and Maths SATS scores, as we wish to find out the effect of other factors on these results. The independent variables will be the range of school characteristics with the addition of average teacher turnover 1996-1999 and the dummy variables for the LEA's. As before, two regressions are carried out separately for the English and Maths variables. The results for this question are in table 3.

These results indicate that teacher turnover does affect pupil attainment. Teacher turnover is a significant determinant (at the 5\% level) of both English and Maths SATS scores. The negative coefficients for this variable suggests that if teacher turnover increases by $10 \%$ SATS scores will decline by 2\% for English and 2.5\% for Maths. This can be expressed, in terms of descriptive statistics, as the upper quartile of schools with the highest teacher turnover achieving, on average, SATS results between 10 and $11 \%$ lower than other schools.

Other characteristics also emerge from this regression as significant determinants of SATS scores. The number of pupils eligible for free school meals has the strongest influence, with schools recording higher percentages in this variable likely to achieve lower SATS results. The negative coefficients for this variable show us a 10\% increase in FSM causes a 5-6\% decrease in SATS scores. The percentage of pupils in the school with special needs emerges as a significant determinant (at the 5\% level) of English SATS scores, although it is noticeable that this variable does not have a significant relationship to Maths results. 


\section{Interpretation of Results}

The links between poverty and higher rates of teacher turnover found in this study reinforce conclusions drawn by commentators such as Zabalza et al. (1979) and Hanushek (2001). In contrast, the arguments of US commentators such as Theobald (1990) are challenged. Theobald stated that teachers were more likely to leave teaching if they taught in a wealthy district rather than a deprived one. He argued this was because in wealthy areas there would be a more marked contrast in salary between teaching and alternative employment opportunities (a teacher's opportunity costs). Such effects seem unlikely to apply in the small geographical area of North London used by this study as a teacher's outside employment opportunities must be relatively equal in all the LEAS covered.

The reasons why this study has detected a relationship between poverty and turnover are difficult to quantify. It is possible that high levels of deprivation in a school are in fact a proxy representing other factors detrimental to teachers working conditions and not measured in the database. These could include for example, school characteristics such as poor pupil behaviour, unsupportive parental attitudes, overworked and inefficient school management and an unattractive local environment. Several of the above factors were cited by Ingersoll (2001) as determinants for high teacher turnover. If this is true, it is these factors, as well as deprivation, which need to be addressed to improve teacher turnover in these schools.

The relationship between SATS scores and turnover would seem to show the preference of teachers to work in schools with higher academic performance. This reinforces the conclusions of Mont and Rees (1996) and Hanushek (2001). There are several possible reasons for this trend:

- Exam league tables of each primary school's key stage 2 results were first published in 1996. It seems highly possible that such ranking of school performance has had a detrimental effect on staff morale and job satisfaction in those schools where performance has been well below average. As a result, teacher turnover could be increased.

- Other changes in the late 1990's, such as the national literacy and numeracy hours, introduced a more prescribed and inflexible primary curriculum. These schemes of work were based on national average attainment. It is possible that teachers in schools with low pupil attainment found them more difficult to implement and as a result, became more likely to leave the profession.

- After 1996 the Office for Standards in Education (OFSTED) system of school inspections began to operate fully in primary schools. There is evidence that inspection results are more likely to find that schools from deprived catchment areas, with low levels of attainment are providing less than satisfactory teaching (see OFSTED 2000). A disproportionate percentage of schools of this type are placed on 'special measures' and labelled as 'failing'. This factor could have increased both teacher stress and as a result turnover in those schools affected.

The type of school observed in terms of whether it is community or voluntary aided (usually church schools) is also shown to be a significant determinant of teacher turnover. Voluntary aided schools have, on average, lower rates of turnover. There are three possible reasons for this relationship:

- Firstly, it is possible that a variety of school level factors are improving teachers' working conditions in voluntary aided schools. These might include the school's ethos, level of pupil behaviour and organisation and management. 
- It is also possible as suggested by Gibbons (2002) that voluntary aided schools are selecting pupils on the basis of attainment enhancing characteristics, which cannot be observed. Such selection would undoubtedly enhance teachers working conditions and decrease teacher turnover.

- A third possible reason for lower turnover in voluntary aided schools is that these establishments are tending to recruit teachers with attitudes significantly different to other teachers, perhaps due to religious belief. As a result, this group of teachers are less likely to leave giving this group of schools lower teacher turnover.

The results of this research show that teacher turnover affects pupil attainment as measured by KS2 SATS results. Possible reasons for this relationship relate to the impact of high turnover on a variety of school level factors. Increased levels of teacher turnover seem likely to reduce teacher effectiveness, decrease the efficiency of school organisation and management and increase behavioural problems. Ingersoll (2001) suggests high turnover could affect staff teamwork, the continuity of the curriculum and relationships with pupils, parents and the community. All these factors could significantly reduce student achievement.

\section{Conclusion}

This study has attempted to investigate the relationship between school characteristics and teacher turnover. The analysis completed suggests a group of schools, characterised by an economically deprived intake and low academic attainment, has significantly more difficulty in retaining teachers than other schools. Furthermore, the study also shows that high levels of teacher turnover can be shown to have detrimental effects on pupil progress and achievement. The results of this study suggest a vicious circle has developed for disadvantaged schools. Low attainment and high levels of social deprivation cause higher than average teacher turnover. A rapid turnover of teachers in turn leads to continued low attainment and ongoing staffing problems.

Essentially, two alternative policies have been applied by UK governments to deal with this situation. The alternative options reflect the academic divide on the causes of teacher shortages outlined above. The first option is to pay teachers in deprived schools higher salaries. This policy was used in the 1970s and 1980s in the UK with the addition of the Social Priority Allowance (SPA) to teachers' salaries. However, research in this area by Zabalza et al. (1979) suggests it was not successful in effectively reducing teacher turnover in disadvantaged schools, perhaps due to its flat rate format and limited budget. The SPA was replaced around 1990 by the introduction of 'formula funding'. In theory this system should have allowed salary differentials to remain as schools with deprived intakes received higher budgets. This should have allowed them to pay teachers at a higher rate. However, continued high rates of turnover in schools with a more deprived intake call into question whether these pay differentials are being maintained.

The second option is to improve the school characteristics and poor working conditions prevalent in deprived schools. The present UK Government aims through programs such as 'Sure Start' to focus resources, in areas such as nursery education, towards the most disadvantaged localities. In theory, over a number of years, such early intervention should alleviate many of the disadvantages experienced by pupils in deprived localities, and as a result teacher recruitment and retention could improve. However, such schemes can only be expected to bring results in the long term and will do little in the near future to prevent high levels of teacher turnover continuing.

Despite successive Governments' stated aim to promote equality of opportunity in education, policies in relation to teacher turnover in deprived schools seem to have followed 
a limited and piecemeal approach. The evidence in this study suggests that these policies have had little success in improving teacher turnover in schools with disadvantaged intakes. It seems likely that only compensatory Government policies, aimed at substantially increasing the financial resources available in deprived schools, could have a positive impact on both teachers' salaries and their working conditions. Such policies would be likely, if implemented, to reduce teacher turnover rates in disadvantaged areas to levels, which are not significantly different from turnover rates in other localities.

Correspondence: Peter Dolton and David Newson, Bedford Group, Institute of Education, London WC1A 0AL, UK.

\section{Acknowledgements}

We would like to thank the DfES for providing access to the Database of Teacher Records and the LEASIS data.

\section{References}

Department for Education and Skills (2001) Statistics of Education: teachers/England and Wales, London, Her Majesty's Stationary Office.

Department for Education and Skills (2002) Delivering results: a strategy to 2006, http:/ /www.dfes.gov.uk/

Dolton, P., Chevalier, A. \& Mcintosh, S. (2001) Recruiting and retaining teachers in the UK, LSE, Mimeo.

GibBon, S. (2001) Geography, resources and primary school performance, LSE, Mimeo.

HANusher, E.A., Kain, J.F. \& Rivkin, S.G. (2001) Why public schools lose teachers, NBER working paper no. 8599, http://papers.nber.org/papers/w8599.pdf

Hutchings, M. (1999) Teacher supply and retention in London 1998-99, Teacher Training Agency, University of North London.

InGERSOLL, R.M. (2001) Teacher shortages, teacher turnover and the organisation of schools, American Educational Research Journal, 38, 3, 499-534.

Mont, D. \& Rees, D.I. (1996) The influence of classroom characteristics on high school teacher turnover, Economic Inquiry 34, 152-167.

Office for Standards in Education (2000) National Summary Data Report For Primary Schools, London, Office for Standards in Education.

Sparkes, J. (1999) Schools, Education and Social Exclusion, CASE paper 29, Centre for the Analysis of Social Exclusion, London School of Economics.

StinEBRicKNER, T.R. (1998) An empirical investigation of teacher attrition, Economics of Education Review 17, 127-136.

Theobald, N.D. (1990) An examination of the influence of personal, professional and school characteristics on public school teacher retention, Economics of Education Review, 9, 241-250.

Wiggins, A \& Trmms, P. (2000) Dysfunctional effects of public performance indicator systems: a comparison between English and Scottish primary schools. Paper presented at the European Conference on Educational Research, Edinburgh.

Zabalza, A., Turnball, P. \& Williams, G. (1979) The Economics of Teacher Supply, Cambridge, Cambridge University Press. 